

ENTREVISTA

\title{
La paz no se rinde Entrevista con Olga Behar Leiser $^{1}$
}

Entrevista realizada por

Wilson Díaz Gamba ${ }^{2}$

Jairo Andrés Hernández Cubides y Johan Stephen Antolinez Franco ${ }^{3}$

Wilson Díaz (WD): ¿Desde hace cuánto trabaja los temas de paz y qué enseñanzas le dejó el proyecto de La paz no se rinde?

Olga Behar (OB): Yo he trabajado los temas de la guerra y la paz, era así como se llamaba, hoy se conoce como los temas del conflicto y la búsqueda de la paz y la reconciliación, desde comienzos de la década de los ochenta. Diría que el detonante en mi ejercicio profesional está ubicado en el robo de las armas del cantón norte por parte del M-19, en el año nuevo de 1979; trabajaba en la radio, y hasta ese momento todos los temas que tenían que ver con guerra, se asignaban al periodista que cubría la fuente de orden público, a lo que llamaban crónica roja. Entonces, cualquier cosa que sucediera y que generara una víctima, o generara un enfrentamiento, era un asunto de criminales versus policías, como en el viejo oeste.

Empezó el consejo de guerra en la cárcel La Picota, porque el robo de las armas del cantón sucedió en una época en la que estaba en plena vigencia el Estatuto de Seguridad del presidente Julio César Turbay Ayala. Él expidió una serie de normas sin tener que llevarlas al congreso, normas bajo Estado de sitio, esto le permitió perseguir implacablemente y tener todo tipo de procedimientos, entre ellos la tortura, para atrapar a esos "criminales que habían desafiado el honor militar" por el robo de las 5700 armas.

Entonces, cuando empezó el consejo de guerra, muchos directores y editores de medios vieron cómo fracasaban los periodistas de la crónica roja tratando de cubrir eso, porque no tenían contexto, no tenían comprensión de la política, porque no entendían la historia de este país. Entonces, no solamente yo, sino muchos otros periodistas

\section{cualquier cosa} que sucediera

y que generara una víctima, o generara un enfrentamiento, era un asunto de criminales versus policías, como en el viejo oeste. de diferentes medios, llegamos al consejo de guerra porque fuimos asignados a esa fuente. Eso para mí fue como un gran despertar que me permitió entender mucho mejor el conflicto colombiano, y a partir de ahí, empecé a trabajarlo no solo mediáticamente sino desde el punto de vista académico también.

Andrés Hernández (AH): ¿cómo narrar la paz y cómo hablar sobre eso que llamamos paz, sin caer, como usted lo dice en su libro, en ese juego de terminar hablando de la guerra?, ¿cómo construir a partir de allí, y cambiar el discurso?

OB: Yo creo que nosotros tenemos que hacer un cambio de lo que llamo "el chip

Periodista y escritora colombiana con amplia experiencia en prensa, radio, televisión y medios digitales. Es directora de la Unidad de Medios de la Facultad de Comunicación de la Universidad Santiago de Cali, donde también ejerce la docencia.

2 Director IPAZUD

3 Editores Revista Ciudad Paz-ando 
mental”, sobre todo los periodistas que cubrimos conflicto durante dos o tres décadas. Nosotros estábamos habituados a tener una manera de ver el conflicto que hoy tiene que cambiar, y tiene que cambiar porque estamos en un proceso de dejar ese pasado atrás y construir reconciliación. En el plano del periodismo y de la literatura, es a partir de la construcción de la memoria; como periodistas, tenemos todas las herramientas para poder abordar el tema de la memoria.

Johan Antolinez (JA): Cuando uno lee el libro se da cuenta de que las historias y las entrevistas fueron muy difíciles y personales, o es lo que percibimos; en ese sentido, ¿qué tan complejo fue contar la historia del conflicto y qué tan complejo es pensar la paz en el marco de lo que estaban haciendo ustedes en las entrevistas?

OB: Yo creo que lo más difícil fue enfrentarse a un conflicto que ha sido muy doloroso, doloroso para las víctimas, doloroso para los periodistas que tenemos conciencia social y, aunque no lo crean, doloroso para los victimarios. Fue un proceso muy interesante y creo que puse sobre la mesa de la negociación con cada uno de los futuros entrevistados, más de treinta años de respetabilidad en el oficio.

Ellos sabían que quien estaba frente a ellos no iba manipular la verdad, no iba a ocultar, no iba a torcer ni a estigmatizar. Yo, por ejemplo, a las víctimas les decía, "quiero que usted entienda que mi trabajo se enfoca no hacia que usted es una víctima, sino que usted es un ciudadano colombiano o ciudadana colombiana, que sufrió un hecho victimizante, esa es una manera de no revictimizarlo, porque sería ponerle un título sobre la frente; usted es un ciudadano que tiene la capacidad de salir delante, de reconstruir su vida, y si se queda en el plano de la víctima, eso nunca va a suceder". Entonces ese fue el trabajo con las víctimas.

El trabajo con lo que llamamos los victimarios, o los que cometieron hechos victimizantes, fue un diálogo en el que les manifestaba que la verdad va a ir, valga la redundancia, a la Comisión de la Verdad, a la Jurisdicción Especial para La Paz y que la verdad va a estar presente en los encuentros de ellos con quienes sufrieron por esos hechos victimizantes. Pero la verdad empieza por la reconstrucción histórica de los hechos, y creo que ese es un buen punto de partida para que cuando se enfrente a los jueces, a los magistrados, a los fiscales, a teóricos o especialistas de la Comisión de la Verdad, ya sepa cómo abordarlos, ya sepa cómo otorgar su verdad, cómo ofrecerla a esas víctimas.

En el caso del Gobierno, hay una anécdota muy chistosa. Yo le solicité una entrevista al vicepresidente Naranjo y él me la dio de inmediato. Viajé a Bogotá D. C., llegué a la vicepresidencia y llevé un libro de una entrevista que le habían hecho a él - me había parecido un libro muy superficial, un libro que era un éxito literario, un bestseller, como dicen los gringos, pero que uno lo termina de leer y se queda sin saber nada de lo que pasó, puras generalidades-; entonces yo llevaba el libro y dije, aquí hay que romper hielo, porque al fin y al cabo, para ellos en el proceso de estigmatización de los periodistas, yo soy un poco el enemigo.

Entonces, me dije, voy a romper con algo que sea duro y le dije: "bueno, general, le agradezco mucho que me esté recibiendo, me parece fantástico, le agradezco que quiera hablar conmigo". Y antes de empezar la conversación le dije: "quiero decirle dos cosas: la primera, que este libro que tengo en la mano lo traje por dos motivos, uno para que me lo dedique, y dos, para que usted sepa que nada de lo que está aquí es lo que le voy a preguntar", y él pensó que lo había dicho todo para ese libro. Entonces, ¿qué me va preguntar?, dijo, ya verá, no se preocupe, le respondí. Proseguí "lo segundo que quiero decirle a usted que, no solo es el vicepresidente, que fue comandante general, y director general de la policía, sino que todo su ejercicio como policía y oficial ha estado siempre de la inteligencia de la policía, es algo para que le quede claro de una vez por todas...nunca fui amante de Carlos Pizarro". El tipo casi se desmaya de la risa y rompí con segueta ese hielo y de una manera espectacular. Él, después de que casi se cae - le dio mucha risa- dijo: qué buena aclaración, como quién dice, está en los expedientes (risas).

Fue un ejercicio muy lindo, me puse a prueba a mí misma y a mi equipo de trabajo para lograr algo que era muy difícil de hacer en solo ocho meses. Cuando usted firma un documento con una editorial, y una editorial tan seria como la de la Universidad Distrital, es un taxímetro donde le dicen, tal fecha tal cosa, tal fecha tal otra, y cuando a usted le llega un correo diciendo "le queremos recordar que hoy es primero de octubre y que usted, el treinta de octubre, debe haber entregado esto, esto, esto", eso es una espada en la espalda.

Sobre todo porque los primeros cuatro meses no escribimos ni una coma, porque buscar a veintisiete personas y hacer entrevistas de cuatro a seis horas con cada una de ellas, volver a ver a muchos de ellos, ¿a qué hora escribíamos?; además, queríamos tener todas las piezas del rompecabezas. Apenas empezamos el trabajo en marzo y yo entregué mi primer capítulo a finales de agosto de 2017. En la editorial estaban aterrorizados, esto iba a ser el fracaso, esa "diva" de la televisión y del periodismo, nos va llevar al fracaso de esta editorial, debían pensar; claro, nunca me dijeron nada, pero fue un reto verdaderamente para todos, y muy lindo, para qué. 
JA: ¿para usted qué significa el título La paz no se rinde?, porque cuando uno lee el libro, se da cuenta de que hay un sentido de que no podemos rendirnos, pero el principio parece que no le apunta a eso.

OB: A mí me gusta hacer un trabajo colectivo de jugar con palabras y nombres. Debo comentarles que tengo otro libro que presenté recientemente, que se llama $L o$ que la guerra se llevó, que es un poco el sentido de que estamos en unas nuevas condiciones. Entonces quise jugar con esas dos palabras, las de mi primer libro, Las guerras de la paz. El resultado es que un libro va con la paz, el otro va con la guerra que espero que se haya ido, que haya terminado, pero como que nos faltaba para este libro amarrarle algo que lo dijera todo en tres palabras.

Y el genio de la lámpara fue el coordinador de la editorial, Rubén Carvajalino, que me llamó un día y me dijo, mira, necesito que me mandes tu foto para la carátula de La paz no se rinde, yo le dije “¿cómo así?"; Sí, contestó él, así se llama el libro, ¿no te gusta? Mejor imposible, pensé, es el titulazo, y verdaderamente esas pocas palabras juntas dicen que, si nos rendimos, va continuar este conflicto que ha desangrado el país, pero si estamos mencionando la posibilidad de que nos rindamos, quiere decir que la paz no la tenemos todavía entre la mano y que se nos puede escurrir entre los dedos. Entonces es muy simbólico, y le agradezco mucho al coordinador de la editorial de la Universidad Distrital, habérsele ocurrido este título tan maravilloso.

AH: Carolina, su hija nos hablaba de que, en el trabajo de campo, haciendo la recolección de la información, pudieron conocer un lado de esa guerrilla, de ese grupo, más humano. Entonces, cuando usted habla en el libro de los hijos de Jacobo, de los hijos de Manuel, de la guerrillerada, ¿por qué hablar de ellos?, ellos casi no hablan, lo que vemos es lo que está en la foto, en el periódico, en el noticiero, pero los otros que están allí, ¿por qué darles voz a ellos?

OB: Para conocer bien a las Farc, podría decir que hice tres grandes viajes a las Farc. El primer viaje fue a $\mathrm{La}$ Uribe, a Casa Verde, cuando estaba haciendo mi libro Las guerras de la paz. Fueron dos viajes, en el 84 y en el 85, al interior de las Farc, pero de la mano, sobre todo de Jacobo Arenas, porque Manuel era un poco más tímido, era más seco. Jacobo era una caja de música, y como él venía de la vida urbana, obrera, conocía el mundo del periodismo muy bien porque él había hecho periodismo también. En esa primera ocasión, con Jacobo y Manuel, percibí una distancia grande entre ellos dos y la guerrillerada, pero empecé a conocerlos, empecé a ver ese lado humano que está un poco presente en el libro de Las guerras de la paz.

El segundo viaje a las Farc fue para este mismo libro, un año después; quise encontrar otras voces y fue la primera vez que busqué a la segunda generación que se dio a conocer posteriormente en el Caguán. La segunda generación, la que fue al Caguán, yo la conocí, tal vez, catorce años antes, porque fue en el 85 cuando fui al otro lado del plan del Sumapaz, donde empieza el cañón del Rio Duda. Yo sabía que me iban a salir los hijos de los patriarcas, pero no sabía cuáles eran, y me salieron Alfonso Cano y Raúl Reyes, que eran dos muchachos como yo en aquella época, un poco mayores que yo, pero eran finalmente, la segunda generación.

Y después duré mucho tiempo en el que había cosas muy esporádicas por ahí, pero no había estos viajes al interior, de pasar días y semanas de conocer verdaderamente su pensamiento. La tercera oportunidad me la dio La Habana, no fui a La Habana ni una sola vez, pero pude en muchas ocasiones trabajar con ellos estas temáticas.

Finalmente, logramos un libro que no solo relata las interioridades de las negociaciones de La Habana y la firma del Acuerdo de paz, sino que también ofrece la oportunidad de conocer a los actores - también a las víctimas- de medio siglo de conflicto en Colombia. Esa visión de conjunto sobre la historia de la confrontación entre la guerrilla y el Estado permite comprender por qué la guerra es tan terrible para la sociedad colombiana y cómo no podemos desperdiciar esta oportunidad histórica de consolidar la paz. 